\title{
DIPLOMELE LA ARHITECTURĂ - UN MODEL SAU UN CONCURS DE LA CRITICĂ LA ARHITECTURĂ - REZULTATE ȘI SINTEZE ÎN DESIGNUL ARHITECTURAL ${ }^{1}$
}

conf. dr. arh. Daniel Comșa, lect. dr. arh. Marina Mihaila

Universitatea de Arhitectură și Urbanism "Ion Mincu"

dancomsa@yahoo.com,daniel.comsa@uauim.ro,marina.mihaila@arhitectonik.ro

\section{Rezumat}

Dacă arhitectura poate fi înteleasă ca un termen generic și este văzută ca o structură, un modul de gândire, concepere a obiectelor, atunci Arhitectura Arhitecturii cum ar putea fi văzută? Poate fi învățământul formativ din arhitectură un mod de a "arhitectura"/structura Arhitectura? Analiza rezultatului proiectului de diplomă poate constitui un instrument de verificare și de creionare a unor priorități viitoare și a unor noi abilități educaționale de antrenat. Neînțelegeri din proiecte ale studentilor din învățământul de arhitectură ne dovedesc că rezultatele noastre nu sunt la cel mai bun nivel dar în egală masură reușitele studenților pot da un nivel ridicat al școlii cu care sa ne mândrim. La polul opus, expozițiile cu cele mai bune proiecte de diplomă (două sesiuni de susținere anuale cu juriu internațional) dovedesc implementarea unor principii durabile pentru formarea abilităților și demonstratea competențelor necesare unei gândiri sustenabile a viitorului arhitect, produs al școlii de arhitectură. Mai mult, desfășurarea celor două ediții ale competiției internaționale de proiecte de diplomă EAM European Architectural Medals for the Best Diploma Projects (EAM BDP) - , organizate de către UAUIM în parteneriat cu AEEA si ACE - , pune în valoare pe lângă formarea abilităților necesare profesiei de arhitect, și o gândire decizională sintetică și critică asupra organizării premiselor, formulării întrebărilor și a deciziilor corelate pentru atingerea unui rezultat final notabil. Concluzionând, critica de arhitectură poate fi baza aplicabilă a unei analize succinte - critică inclusă de la nivelul de conturare a priorităților unei școli de arhitectură, până la modelul de concepere a unui proiect, care să diminueze erori și să prevină riscuri. Rezultatul unei analize critice în formarea abilităților și demonstrarea competențelor poate constitui un sistem de verificare-comunicare pe paliere multiple a implicării unor principii comune manageriale și curriculare, simplu de aplicat, cu ținte multiple, pentru un spațiutimp sustenabil profesional, și a regândirii unui sistem de produse educaționale: proiect - student - viitor profesionit - comunitate arhitecturală.

Cuvinte cheie: diplome, arhitectură, model, rezultate educația universitară, UAUIM

\footnotetext{
${ }^{1}$ Articolul face parte din studiile Biroului de Relații Academice Internationale, Universitatea de Arhitectură și Urbanism „Ion Mincu” București. Articolul este realizat de autori în urma prezentării (realizate de autori) în cadrul Simpozionului "Arhitecturi Comtemporane. De la obiect la teritoriu" 23 March 2017 CSAU -UAUIM, Romexpo București http://www.uauim.ro/evenimente/simpozion-arhitecturi-contemporane-2017/
} 


\section{In căutarea performanței de demers: proiectele de diplomă}

\section{Introducere}

Prezentul articol își propune să prezinte evenimentele diplomelor de arhitectură ca dublă paradigma educațională: răspunsuri sintetice cumulative la/și în paralel cu formularea temelor de proiecte, și strategia educațională (UAUIM, 2016) pentru validarea academic-universitară la nivelele propuse - interne, naționale și internaționale. Identificarea în paralel a priorităților finale ale proiectelor și țintelor de atins in educația universitară (UAUIM, 2016) este metoda propusă pentru (re)evaluarea succesului academic. Totodată, îndeplinirea și corelarea cu standardele internaționale la nivelul produselor academice dar și arhitecturale, sunt alte ținte prioritare. Cu alte cuvinte, nivelul cunoștințelor, orientarea tematică și formarea profesională sunt ținte ce trebuie corelate cu nivelul și prioritățile curriculare și formative ale școlilor de arhitectură locale, Europene și internaționale.

Articolul își propune să vorbească despre proiectele de diplomă de arhitectură, ca status contemporan aliniat domeniului performant dedicat. Cele mai multe diplome se doresc în sine noi emergențe profesionale, un model sau un concurs de idee aplicată, participând la un concurs permanent de idei și exprimare, multe militând pentru un status/ statement dar și pentru o readucere în prim plan a unor viziuni teoretice fundamentale. Diplomele (proiectele de diplomă) în sine sunt și se doresc declarații arhitecturale - unele ating propria ștacheta anunțată, altele clachează la mici detalii de proces de fabricare a demersului. Multe diplome sunt însă un succes real, în abordarea sintetică de design arhitectural - ca rezultate finale, și în căutarea elementelor de marcare a performanței de demers: de fabricare detaliată a unui rezultat final de excelență.

Articolul nu își propune să definească școala de arhitectură, dar rezultatele de succes cât si cele medii ale proiectelor de diplomă aduc și readuc în prim-plan excelența educațională și o pot reașeza pe harta performanței de vârf din domeniu. Momentul actual regăsește UAUIM ca școală de arhitectură cu performanță în ascendență de peste 20 de ani, într-un proces de continuă modernizare și racordare la standarde inovative și tehnologice. UAUIM pastrează și lucrează la poziția și viziunea sa identitară ca școala de arhitectură, prin atelierul de proiectare de arhitectură, baza sintetică a pedagogiei academice (arhitecturale), atelier ce este permanent susținut și corelat contextului cultural și social - național și internațional -, în variante flexibile de predare și susținere a procesului didactic adaptat prin echipele tutoriale (mentori - profesori) de indrumare, urmărind dezvoltarea de abilități formative integrate viitoarei profesii, în variantele actuale extinse pe care piața internațională le oferă.

\section{Metodologie}

Metodologia articolului se bazează pe etichetarea principiilor și rezultatelor, și în paralel, pe analizarea răspunsurilor - în special a colecțiilor de răspunsuri și exemple de succes. Autorii sunt preocupați de subiectul educației ca reflexie curriculară, dar și de cercetare, datorită implicării ca tutori în procesul sintetic master integrat, și corelat cu topicurile principale de cercetare (arhitecturală) contemporană reflectate și de procesul educației, și a cercetării prin proiect, inclusiv la nivel de exercițiu de învățare. Articolul se dorește și o trecere în revistă pentru organizarea și conceptul validării diplomei școlii de arhitectură, reflectat în activitatea Biroului de Relații Academice Internaționale, Universitatea de Arhitectură și Urbanism "Ion Mincu" București. Activitatea de organizare a comisiilor internaționale de diplome ca și experiența sesiunilor de dezbatere și mesele rotunde (Anexa 1, Anexa 2) cu membri acestor 
comisii internaționale la care participă și profesorii-cadre didactice UAUIM, este una din bazele relevante ale acestui articol - comunicarea principiilor și analizarea rezultatelor. O altă experiență care stă la baza articolului este evoluția discuției între membri UAUIM (UAUIM, 2016) - ACE (ACE, 2016) - AEEA (AEEA, 2016) pe baza organizării concursului internațional pentru medalia de arhitectură pentru proiectele de diplomă: EAM - European Architectural Medals for the Best Diploma Projects (EAM BDP) (EAM BDP, 2016). O premisă de formulare a unor creșteri de competență dincolo de experiența curriculară este desprinsă și din mai noua tradiție a colaborărilor internaționale IAESTE (IAESTE, 2016), ce au în vedere susținerea pregătirii aplicate - practica în birourile de arhitectură. Un elocvent review pentru diplomele de arhitectură îl constituie publicațiile și albumele cu cele mai bune diplome UAUIM, dar și albumul fiecărei ediții EAM BDP, și nu în ultimul rând ilustrările proiectelor de diplomă predate către ANUALA Arhitectură București (ANUALA, 2016) (organizată de către OAR - Ordinul Arhitecților din România) (OAR, 2016).

\section{Diplomele la arhitectură}

\section{Demers arhitectural-educațional}

Dacă Arhitectura poate fi înteleasă ca un termen generic și este văzută ca o structură, un modul de gândire, concepere a obiectelor, atunci Arhitectura Arhitecturii cum ar putea fi văzută? Translatând termenul de arhitectură propriei educații, un sistem de gândire este implicit formării viitorilor arhitecți ca produse sustenabile în domeniul practicii aplicate și/sau teoretice. Nu degeaba un sistem de gândire propriu, explicabil doar parcă pentru cei puțini devine un mod de comunicare între membri academiei de arhitectură de pretutindeni, deopotriva profesori și studenti. De la alegerea unei metode până la alegerea unei cele mai bune soluții pentru un demers, ilustrări de la cele mai tehnice până la cele conceptuale și de decizie au devenit marca a domeniului. De ex.cartea de idei arhitecturale a lui Matthew Frederick (Frederick, 2007) ilustrează un mod de gândire specific școlii de arhitectură de pretutindeni - într-un limbaj specific construcției de idei arhitecturale - grafic însotit de cuvinte cheie și scurte descrieri de gândire sistemică ce au făcut deja istoria domeniului.

Numit specific unor criterii de final educativ - master integrat, ultimul nivel de aplicare a cunoștințelor își propune ca prin exerciții arhitecturale - proiecte în cadrul atelierelor de arhitectură să pună bazele implicării cunoștințelor acumulate pe toate palierele educației și a cursurilor formative, totodată cu învățarea unor metode, ca în final să poată propune viitorilor arhitecți formularea unui proiect complex - cu întrebări și soluționări, tematică și demers conceptual propriu, să testeze deopotrivă gândirea sistemică multiplă, racordarea la îngrijorările și emergențele contemporane ale arhitecturii, dar și a unui aport propriu (calitativ) pe care viitorul profesionist le va aduce domeniului (Irșai\&UAUIM, 2011).

De multe ori Arhitectura Arhitecturii va cuprinde pe lângă abilități și competențe scrise și formulate prin curriculă, maniere și algoritm multiplu de gândire, ambele contând pentru demonstrarea stabilității formale învățării dar și aplicării îndrumării în cadrul atelierelor de proiectare arhitecturală. De la colectarea ideilor până la decodificare și punerea în primă ecuație a unui început până la configurarea unui demers conceptual si parcurs arhitectural, proiectele - ca subproduse formale ale educației- se situează între abilitatea designului vederii de ansamblu, aplicabilitate și un format integrat posibilităților reale și educaționale corelate. 
Bază a educației și culturii arhitecturale pentru mulți arhitecți de succes la nivel național si internațional, școala de arhitectură UAUIM pătrează nivelul tradiției manierei de lucru și a elaborării proiectului detaliat, și în ultimii 20 de ani căstigă expertiză în sustinerea performanței de demers a fabricării designului și a motivării consecventei declarațiilor conceptuale, devenind și sorindu-se un spațiu academic cu inclinații artistice dar cu reale valențe practice și abilități tehnice.

Experimentele și experiența academică, dar și baza în practica de arhitectură demonstrează și alte inputuri de inserat în căutările universitare: cultivarea sensibilității artistice și creativității (Mitrache, 2013), pedagogiei aurale... (Bărbuică, 2013), dar și a abilităților complementare și a deprinderilor formative antrenate în afara orelor dedicate curriculei, și anume în cadrul desfășurărilor workshop-urilor/atelierelor bazate pe cercetare-discuție și dezbatere-inovație în gândirea arhitecturală (Sfinteș, 2017).

Rezultatele din proiectele de diplomă sunt fără doar și poate rezultatul antrenamentului în atelierul de proiectare arhitecturală, desfașurate pe durata a 12 semestre, sub inputul de integrare curriculară și de demers - ca metodă de lucru în gandirea arhitecturaăa. De multe ori un demers susținut corect și cu validarea tuturor punctelor de verificare de design poate sustine și asigura un rezultat de calitate sau de excelență. Alteori, partea artistică, uneori intuită, și apoi verificată prin lista de design integrat, este rețeta unei abordări curajoase și care aduce în prim plan școala de arhitectură (de exemplu: medaliile obținute de absolvenții UAUIM).

\section{Discuții asupra proiectului (final): diploma}

Poate fi învățământul formativ din arhitectură un mod de a "arhitectura"/structura Arhitectura?

Analiza rezultatului proiectului de diplomă poate constitui un instrument de verificare și de creionare a unor priorități viitoare și a unor noi abilități educaționale de antrenat. Neînțelegeri din proiecte ale studentilor din învățământul de arhitectură ne dovedesc că rezultatele noastre uneori nu sunt la cel mai bun nivel sau ca există o lipsă în fabricarea designului arhitectural (în proiectul de școală), dar în egală masură reușitele studenților pot da un nivel ridicat al școlii cu care să ne mândrim. Neînțelegerile din aceste proiecte pot opune algoritmi de coerență minimă educațională unora de sustenabilitate a viitorului profesionist: 1.complicat vs. complexitate în formularea gândirii designului arhitectural, 2.aplicarea unor mode aleatorii vs.formularea unor principii senzorial-compozitionale., 3.stilistică formală nefondată vs.enunțarea unor principii pornind de la interfața spațiului dedicat/din design, 4.aplicarea unor detalieri standard vs.conturarea soluțiilor bazate pe design propriu, 5.elemente de sustenabilitate formală vs.unei sustenabilități care raspunde pe toate palierele responsabile, 6.subiect narativ vs.emergență tematică.

La polul opus, expozițiile cu cele mai bune proiecte de diplomă (două sesiuni de susținere anuale cu juriu internațional) dovedesc implementarea unor principii durabile pentru formarea abilităților și demonstratea competențelor necesare unei gândiri sustenabile a viitorului arhitect, produs al școlii de arhitectură. (Barac, 2012) Două tendințe generale pot demonstra nivelul de vârf educațional prin proiectele de diplomă ale școlii de arhitectură: modelul si competiția de idei incluse modelelor - concursul sau expoziția comparativă pentru alegerea celor mai semnificative modele pentru a enunța sensul educației mediului academic arhitectural, dar și pentru menținerea unei tradiții a școlii de arhitectură (Dobre, 2016). 
Vizibilitatea proiectelor de diplomă reflectă maniere interpretative contemporane, dar și ideile cuprinse. Acestea îndreaptă de asemenea aceste proiecte către un model arhitectural expunerea de tip model-concurs fiind inclusă unei comptetiții vizavi de rezultate: acreditarea RIBA part II a diplomelor absolvenților - fiind un target pentru școala de arhitectură, - OAR ca breaslă profesională validând internaționalizarea diplomei și verificarea standardelor prioritare pentru unversități prin desfășurarea juriilor internaționale ale sesiunilor de proiecte de diplomă: Alumni împreună cu IAESTE (Comşa, 2012) asigurând verificarea tiparelor postacademice și de mentorat. Deschiderea Anualei de Arhitectură București către înscrierea în selecția finală a expoziției a proiectelor de diplomă, susține același demers educațional, încurajat ca fiind unul continuu în carieră.

Mai mult, desfășurarea celor două ediții ale competiției internaționale de proiecte de diplomă EAM - European Architectural Medals for the Best Diploma Projects (EAM BDP) - , organizate de către UAUIM în parteneriat cu AEEA si ACE - , pune în valoare pe lângă formarea abilităților necesare profesiei de arhitect, și o gândire decizională sintetică și critică asupra organizării premiselor, formulării întrebărilor și a deciziilor corelate pentru atingerea unui rezultat final notabil.

\section{De la critică la arhitectură - rezultate și sinteze în designul arhitectural}

Educația în școlile de arhitectură poate diferi, dar ea este structurată similar pe câteva principii curriculare asemănătoare, dincolo de țară sau sistem de învățământ - școala de arte sau scoala tehnică. Competențele sunt formulate asemanător, rezultatele pot fi însă foarte diferite. Proiectul de diplomă (împreuna cu disertația - studiul de cercetare care însoțește diploma pe parcursul evoluției conturării demersului) pot fi considerate un examen final și de maturitate - validează sau invalidează uneori produsul arhitectural, astfel putând trage concluzii directe. Competențele de ordin general se referă la capacitatea de a concepte proiecte valabile estetic și tehnic. Competențele orientate pe domeniile cu emergențe în cercetare (Jöger et al., 2016) - arts\&humanities (incluzând pe lângă arte vizuale și performative, filosofie și istorie), social sciences (științe sociale, inclusiv urbanism, acțiuni sociale, peisagistică, context și design urban), tehnologii și structuralitate spațială, și elemente de aplicabilitate în domeniul construcțiilor inclusiv sustenabilitate (UAUIM, 2016).

Similar artei expresioniste a lui Pollock (Art-Madrid, 2016), arhitectura este în permanentă redefinire de algoritmi de o complexitate din ce în ce mai mare. Reluând comparația probabil că ar putea fi nu numai subiectul unei puneri în ecuație relațională cu alte domenii de înrolare socială și comunicațională (Mihaila, 2014) dar și într-o ecuație fractal expresionistă. Chiar dacă pentru propri membri poate părea mereu necomunicată sau nefocusată, arhitectura ramâne un domeniu de vârf, influențată mereu de tendințele școlilor de arhitectură dar influențând înapoi educația, standardele și redefinind istoria domeniului prin emergența zidirilor recente.

Mentoratul ramâne un principiu de bază, un model educațional care clădește relații și influențează domeniul direct dincolo de pragurile școlilor de arhitectură, inclusiv în profesie. (Mihaila, 2015) Asadar dezvoltarea unor criterii integrate pe toate categoriile de produse educationale (AEEA, 2016) - de la proiect la viitorul architect, de la membru in echipa de indrumare pana la mentor, si pana la curricula toate acestea ar trebui sa fie rolul unei singure gândiri integrate. Asumarea punctelor tari și slabe ale evaluărilor periodice constituie o gândire asumată în designul architectural, asemeni unei gândiri critice asupra produselor 
educaționale orientate către rezultate sustenabile imediate. Concluzionând, critica de arhitectură poate fi baza aplicabilă a unei analize succinte - critică inclusă de la nivelul de conturare a priorităților unei școli de arhitectură, până la modelul de concepere a unui proiect, care să diminueze erori și să prevină riscuri. Rezultatul unei analize critice în formarea abilităților și demonstrarea competențelor poate constitui un sistem de verificare-comunicare pe paliere multiple a implicării unor principii comune manageriale și curriculare, simplu de aplicat, cu ținte multiple, pentru un spațiu-timp sustenabil profesional, și a regândirii unui sistem de produse educaționale: proiect - student - viitor profesionit - comunitate arhitecturală.
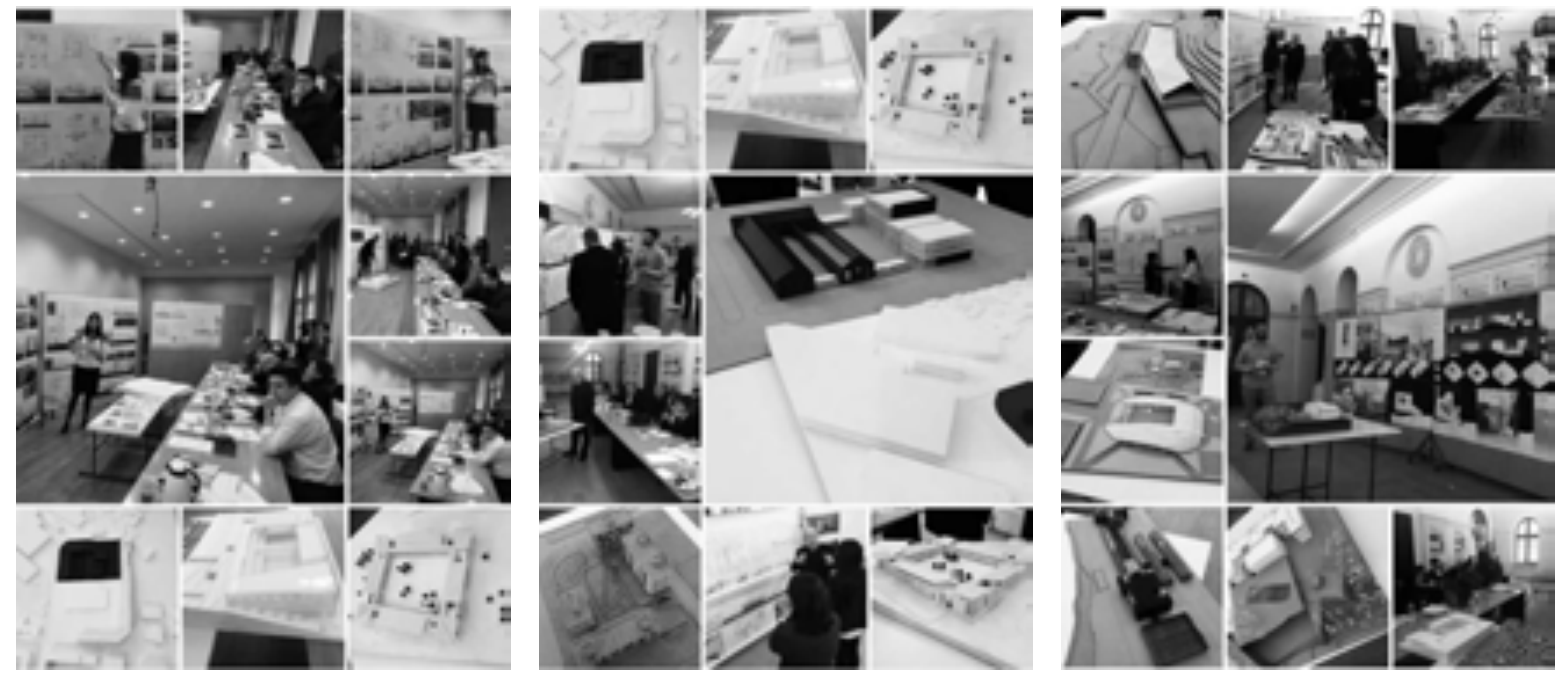

Fig. 1. Montaj imagini ilustrare atmosfera comisiilor internaționale pentru jurizarea proiectelor de diplomă (sesiunea Martie 2017), Facultatea de Arhitectură, UAUIM. Sursa: pagina facebook Birou RAI, UAUIM (UAUIM, 2017).

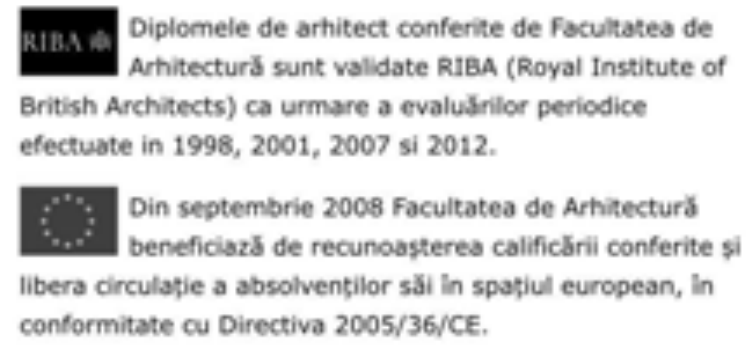

Fig. 2. „Diplomele de arhitect conferinte de Facultatea de Arhitectură sunt validate de RIBA (Royal Institute of British Architects) ca urmare a evaluărilor periodice efectuate în 1998, 2001, 2007 și 2012”; „Din septembrie 2008 Facultate de Arhitectură beneficiază de recunoașterea calificării conferite și liberă circulație a absolvenților săi în spațiul european, în conformitate cu Directiva 2005/36/CE.". Print screen, UAUIM site (UAUIM, 2017). 

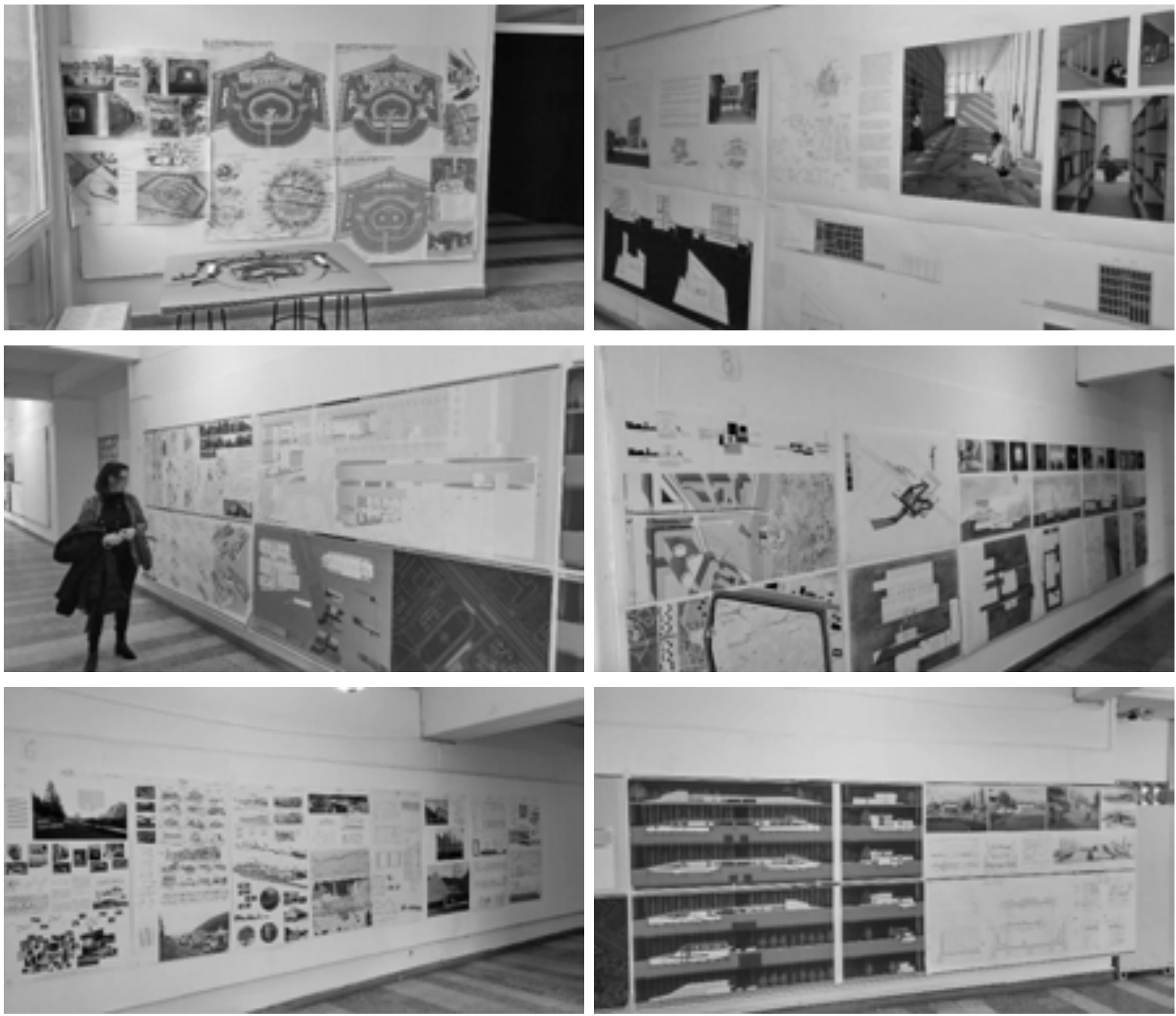

Fig. 3. Imagini de la expoziția cu cele mai bune diplome de arhitectură, sesiunea Martie 2017. Foto: Daniel Comsa, 2017.

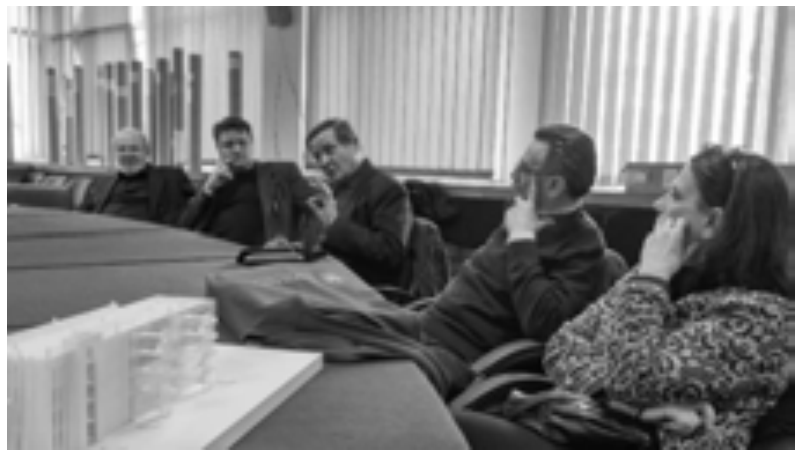

Fig. 4. Masa Rotundă: Concluzii Comisii Diplome Arhitectură Seziunea Martie 2017, Sala Consiliu, UAUIM: discuții între profesorii din comisiile de diplome; în imagine: Profesor arh. James Horan - Irlanda, Professor arh. Vlatko Korobar - Macedonia, Profesor arh. Juhani Katainen - Finlanda, Profesor dr.arh. Ferenc Sebesteny

- Ungaria \& Profesor arh. Alessandra Capanna - Italia. Foto: Daniel Comsa, 2017. 


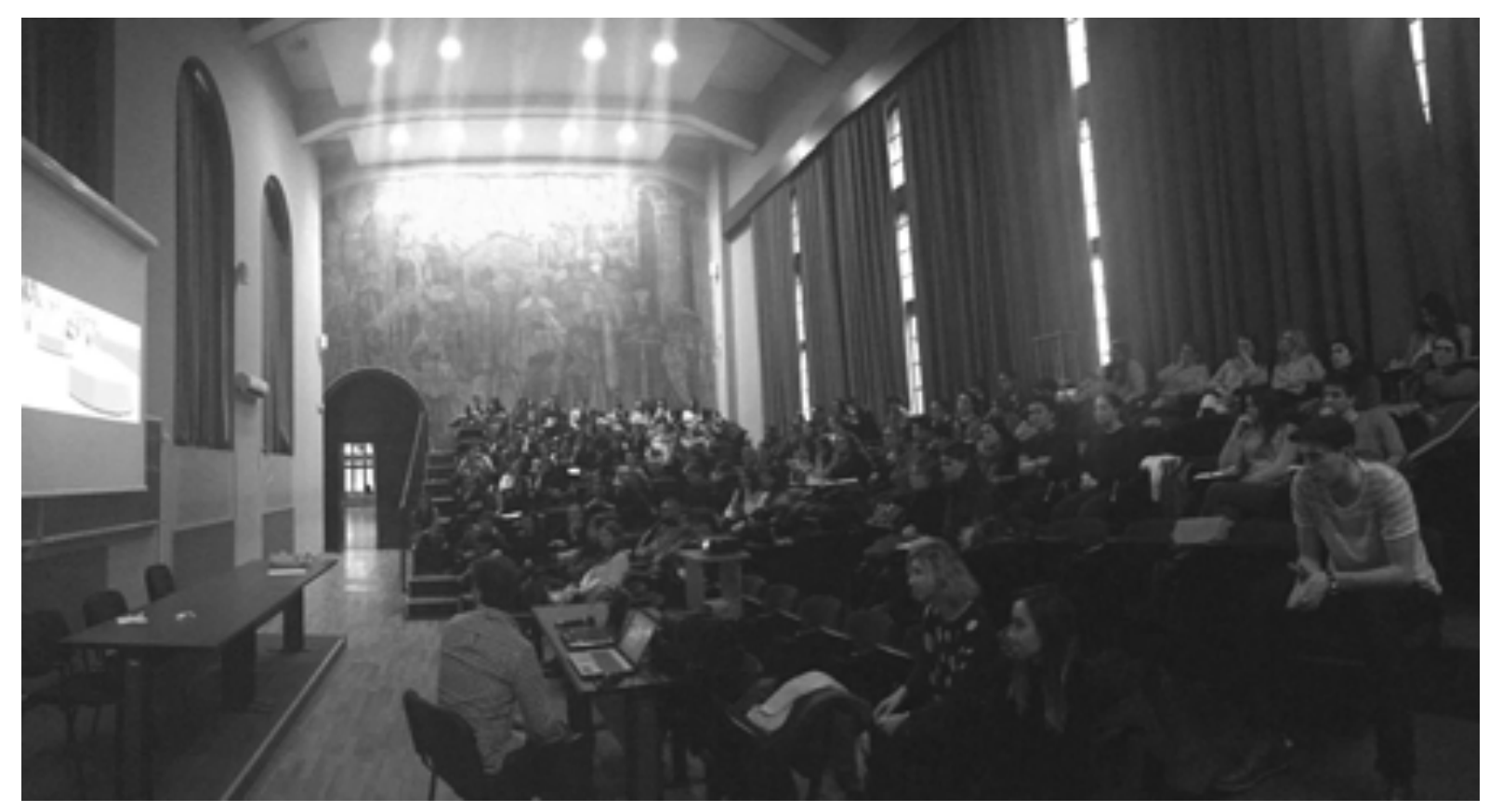

Fig. 5. Sala Frescelor, UAUIM, București - imagine de la conferința interactivă IAESTE pentru diseminarea informațiilor și locurilor de practică Martie 2017, în care studentii foști participanți practică IAESTE au prezentat stagiile și experiențele profesionale. Foto: Marina Mihaila, 2017.

\section{Anexa 1. Masa rotundă concluzii SESIUNE DIPLOME Iulie 2017, UAUIM 7 Iulie 2017}

\section{Rezumat}

Masa rotundă concluziile Sesiunii de Diplome Iulie 2017 (5-6 Iulie 2017), UAUIM, a reunit în Sala de Consiliu a UAUIM București 7 lulie 2017, membri managementului universității, profesorii participanți în cadrul comisiilor de evaluare (11 comisii, a câte 8 membri+1 secretar, 2 coordonatori generali) și personalul academic al universității printre care și îndrumători ai proiectelor de diplomă. Intâlnirea a fost inițiată de Rectorul UAUIM Prof.Dr.Arh. Marian Moiceanu și de către Decanul Școlii de Arhitectură UAUIM Prof.Dr.Arh. Georgică Mitrache, prezentând rezultatele sintetice ale Sesiunii de Diplome și procesul de votare al celei mai bune diplome - masa rotundă a fost precedată de Expoziția celor mai bune proiecte de diplomă, și profesorii participanți în cadrul Comisiilor de Evaluare au fost invitați să voteze pentru cel mai bun proiect expus. După procedura de votare și alegere a celor mai bune trei proiecte de diplomă din cadrul sesiunii prezente, discuțiile au fost inițaite, și fiecare profesor a enunțat opiniile sale asupra nivelului proiectelor de diplomă (referindu-se la comisia proprie) și a nivelului studenților, subiectelor, importanței temelor (alese), relației cu domeniul artelor și a contextului urban, designul programelor arhitecturale și complexitatea abordării si a rezultatului. Ca un input general din enunțările concluziilor profesorilor, anul acesta studenții au crescut spectaculos nivelul prezentării cunoștințelor de limbă engleză - discursul și dialogul în arhitectură dar și exprimarea rezultatelor pozitive asupra propriilor proiecte - , de asemenea observându-se un număr crescut de proiecte bune comparativ cu anii din urmă, pe masură ce proiectele cu o abordare slabă continuând să existe, și să aiba acces în procesul de jurizare finală de diplomă. Dezbătând procesul de acreditare și sistemul de certificare de calitate în educație ca fiind verificat de derularea Comisiilor Internaționale de Jurizare/Evaluare, câteva 
rezultate ale discuțiilor au fost: recomandarea ca toate fazele proiectului să fie expuse - in special Prediploma, sublinierea evoluției proiectului și gândirea conceptuală din spatele expunerii diplomei, și de asemenea lucrul cu modelul și expresia de arhitectură pentru asigurarea unui vocabular și a unui rezultat de arhitectură contemporană. Masa rotundă a fost presidată de către Rectorul UAUIM Prof.Dr.Arh. Marian Moiceanu, Decanul Școlii de Arhitectură UAUIM Prof.Dr.Arh. Georgică Mitrache, și de către Coordonatorii Generali: Pres.Prof.Dr.Arh. Emil Barbu Popescu și Conf.Dr.Arch. Daniel Comșa, Director Birou Relații Academice Internaționale.

\section{Anexa 2. Masa rotundă concluzii SESIUNE DIPLOME Martie 2017, UAUIM 3 Martie 2017}

\section{Rezumat}

Sesiunea de primăvară a Proiectelor de Diplomă este organizată ca a doua serie de comisii internaționale de jurizare/evaluare, cumulând între 3 și 6 comisii în fiecare an, având același număr de 8 profesori în comisie (și 3 comisii internaționale de jurizare în această sesiune, martie 2017). Masa rotundă concluzii SESIUNE DIPLOME Martie 2017, UAUIM 3 Martie 2017, a dezvoltat o discuție extinsă asupra nivelului școlii de arhitectură, bazat nu numai pe prezența celor mai bune sau excelente proiecte de diplomă, dar și pe evaluarea majorității și a nivelului proiectelor slabe. Această discuție este comună investigărilor și intrebărilor din cadrul școlilor de arhitectură de pretutindeni, urmărind părerile ca răspuns al rezultatelor educației, împreună cu așteptările asupra viitorilor specialiști, arhitecți. Observațiile profesorilor au fost legate de aplaudarea celor mai bune rezultate, mult mai prezente și performante față de ultimii ani, recomandarea standardizarii prezentării - orale și desenate -, prezența obligatorie a declarației de interes asupra arhitecturii, capacității conceptuale, și a istoriei proiectului, poate o introducere care să fie facută comisiei înainte de susținerea publică a proiectului de diplomă. Recomandările vizavi de prezentările urmărite au fost: focusul trebuie să atingă tehnologia și cercetarea, ca și studiul formei în machetă, relația dintre prediplomă (ca predesign) și diplomă trebuie să fie discutate, și referințele comisiilor anterioare trebuie să fie subliniate. Alte prescripții au relaționat către admiterea (având aviz favorabil din partea tutorului) pentru susținerea prezentării publice a proiectului de diplomă, și a prezenței studenților din anii anteriori (diplomei) pentru asistarea și învățarea din experiența discutării proiectelor finale de absolvire. Masa rotundă a fost presidată de către Rectorul UAUIM Prof.Dr.Arh. Marian Moiceanu, Decanul Școlii de Arhitectură UAUIM Prof.Dr.Arh. Georgică Mitrache, și de către Coordonatorii Generali: Pres.Prof.Dr.Arh. Emil Barbu Popescu și Conf.Dr.Arch. Daniel Comșa, Director Birou Relații Academice Internaționale.

\section{Referinţe}

AEEA / EAAE. EAAE GA \& CONFERENCE 2016. (2016). A case study discussed in the context of institutional profile(s) and the future of architectural education. Delft: TU Delft Faculty of Architecture. pp. 53-54

Barac M. (2012). Ion Mincu University of Architecture and Urbanism, Romania. in The Architectural Review 232(1386). pp. 108-109 
Bărbuică L. (20130. Towards a New Aural Pedagogy for Architecture. in Procedia Social and Behavioral Sciences 92. pp.92-97

Comşa D. (2012). The cultural role of the international exchanges on architectural education through IAESTE. in Proceedings Book ICAR2012, Chapter: Beyond discipline(s) - architectural education and research, Bucharest: EUIM.

Comşa D. (2014). Architectural competition seen as a research method. in Lucrarile Conferintei de Cercetare in Constructii, Economia Constructiilor, Urbansim si Amenajarea Teritoriului, Volum 1-8 20112014, Chapter: Arhitectura, (Eds.): A.Petrișor, V.Meiță Bucharest: NR\&DI URBAN-INCERC. pp. 15-16

Dobre A-M. (2016). „Examenul de Stat” şi Proiectul de diplomă în Şcoala românească de Arhitectură a anilor '50. / Final Exams and Diploma Project in the Romanian School of Architecture of the 50's. in Argument 8/2016. pp. 47-60

Frederick M. (2007). 101 Things I Learned in Architecture School. London: MIT Press.

Jöger B., Comşa D., Panait A., Mihaila M., Zamfir (Grigorescu) M., Diaconescu O., Sfinteş A-I., \& Armenciu D.N. Building an Architectural Discourse_ A Review on Scholarly Academic Space, UAUIM. in EURAU 2016 Proceedings, 2016. pp. 445-452

Mihaila M. (2014). Communicating Architecture - activities, actions, exercises, mission statements. in LUMEN: Transdisciplinarity and Communicative Action. Bologna: Medimond Monduzzi International Proceedings 2014. pp. 465-469

Mihaila M. (2015). Mentoring Architecture: Contemporary Status as Overview. in Working Papers LUMEN MEPDEV 2015, lași: LUMEN, 2015. pp. 265-266

Mitrache A. (2013). Spatial sensibility in architectural education. in Procedia Social and Behavioral Sciences 73. pp.544-548

Sfinteș A. (2017). Workshop: Locuri În Afara Limitei / Places Out Of The Limit. in Argument 7/ 2017. pp. 395-406

\section{Webografie}

ACE. (2016). The Architects' Council of Europe. http://www.ace-cae.eu/ (accesat 8.04.2017)

AEEA / EAAE. (2016). European Association for Architectural Education. http://www.eaae.be/ (accesat 8.04.2017)

ANUALA. (2016). Anuala Arhitectură București / Bucharest Architecture Annual. 2016. http://www.anuala.ro/ (accesat 8.04.2017)

Art-Madrid. (2016). Pollock is Pollock. 13th Contemporary Art Fair, Feb.2018. http://www.artmadrid.com/en/news/Jackson-Pollock-A-Collection-Survey-at-MOMA-Museum (accesat 8.04.2017)

EAM BDP. (2016). European Architectural Medals for the Best Diploma Projects. https://eam.uauim.ro/ (accesat 8.04.2017)

IAESTE. (2016). The International Association for the Exchange of Students for Technical Experience (IAESTE). 2016. http://www.iaeste.org/about-iaeste/ (accesat 8.04.2017)

Irșai I. (2011). Universitatea de Arhitectură şi Urbanism „Ion Mincu”- Bucureşti, Facultatea de Arhitectură, 6-7 Iulie 2011. in Arhitectura, 2011. http://arhitectura-1906.ro/2011/10/universitatea-dearhitectura-si-urbanism-\%E2\%80\%9Eion-mincu\%E2\%80\%9D-bucuresti-facultatea-de-arhitectura-6-7iulie-2011/ (accesat 8.04.2017) 
OAR. (2016). Ordinul Arhitecților din România (Romanian Architects Order). http://www.oar.archi/ (accesat 8.04.2017)

RIBA. (2016). Royal Institute of British Architects. https://www.architecture.com/ (accesat 8.04.2017)

UAUIM / IMUAU. (2016). "IOn Mincu” University of Architecture and Urbanism" Bucharest. http://www.uauim.ro/ (accesat 8.04.2017)

UAUIM / IMUAU. (2016). Plan de învățământ 2016-2017, anul VI (sem. 11 și 12). Curriculum 2016-2017, 6th year (sem. 11 and 12). http://www.uauim.ro/facultati/arhitectura/arhitectura/planuriinvatamant/6/ \& http://www.uauim.ro/en/faculties/architecture/architecture/curricula/6/ (accesat 8.04.2017)

UAUIM / IMUAU, Moiceanu M., Mitrache G., \& Stănculescu M. (2016). Studiul de Fundamentare a Prediplomei 2016-2017. (Fondation Study for Diploma Project). Departamentul Sinteza Proiectării de Arhitectură. (Synthesis of Architectural Design Department), 2016. http://www.uauim.ro/departamente/sp/teme6/

http://www.uauim.ro/departamente/sp/teme6/2016-

2017/Studiul\%20de\%20fundamentare\%20a\%20prediplomei\%202017 (accesat 8.04.2017)

UAUIM / IMUAU. (2016). Ghidul Studentului (Student's Guide) 2015-2016/ 2016-2017. Bucharest: Editura Universitară „Ion Mincu”, 2016. pp. 57-71 http://www.uauim.ro/facultati/arhitectura/ \& http://www.uauim.ro/facultati/arhitectura/Ghidul\%20studentului_ARHITECTURA_2016-2017.pdf (accesat 8.04.2017)

UAUIM, RIBA \& EUA. (2016). Managementul calitatii educatiei - Raport RIBA, raport EUA etc. UAUIM / IMUAU. "IOn Mincu" University of Architecture and Urbanism" Bucharest. 2016. https://www.uauim.ro/universitatea/managementul_calitatii_educatiei/ (accesat 8.04.2017)

UAUIM. (2016). UAUIM Facebook page: facebook page RAI Office - International Academic Relations Office, UAUIM / IMUAU: https://www.facebook.com/UAUIM-International-Academic-Relations-Office701443153359998/ photo before collage : Marina Mihaila, Marius Voica, 2017 (accesat 8.04.2017) 


\title{
ARCHITECTURE DIPLOMA PROJECTS - A MODEL OR A COMPETITION
}

\author{
FROM CRITIC TO ARCHITECTURE - RESULTS AND SYNTHESIS IN ARCHITECTURAL \\ DESIGN ${ }^{1}$
}

assoc. prof. PhD. arch. Daniel Comșa, teach. assist. PhD arch. Marina Mihaila

University of Architecture and Urbanism "Ion Mincu"

dancomsa@yahoo.com, daniel.comsa@uauim.ro,marina.mihaila@arhitectonik.ro

\begin{abstract}
If architecture could be understood as a generic term and seen as a structure, a thinking module of conceiving objects, so the Architecture of Architecture how might be perceived? Could formative education from architecture field be a way to "architecture"/ structure Architecture? The result analysis on the diploma projects could be a verifying instrument for sketching the future priorities and of new educational abilities to train. Misunderstandings from the students projects within the architecture education that are proving our results are not at the best level but equally the successful results of the students could set a high level of architecture school to be proud of. On the other direction, exhibitions with best diploma projects (two sessions of annual public defense having international jury) prove some durable principles implementing for forming abilities and demonstrating the necessary competencies for a sustainable thinking for the future architect, product of school of architecture. More, the development of the two editions of the international competition for architecture diploma projects EAM - European Architectural Medals for the Best Diploma Projects (EAM BDP) - organized by UAUIM / IMUAU in partnership with AEEA and ACE, value besides the abilities formation needed for the architect profession, also a synthetic decisional and critical thinking upon premises organizing, formulating questions and of the correlated decisions for targeting a final notable result. Concluding, architecture critic could be the applicable basis of a succinct analysis - included critic for the priority defining level of school of architecture, towards the model of conceiving of a project to diminish errors and prevent risks. The result of a critical analysis in forming abilities and demonstrating competencies could constitute a system of verification-communication on multiple levels of few common managerial and curricula's principles implication, simple in appliance, with multiple targets, for a sustainable professional space-time, and for rethinking a system of educational products: projectstudent-future professional-architectural community.
\end{abstract}

Cuvinte cheie: diplome, arhitectură, model, rezultate educația universitară, UAUIM

\footnotetext{
${ }^{1}$ Article is part of International Academic Relations Office, „Ion Mincu” University of Architecture and Urbanism” Bucharest (UAUIM IMUAU). The article is written by the authors following their presentation within Symposium "Contemporary Architecture. From object to territory" 23 March 2017 CSAU - UAUIM / / IMUAU, Romexpo Bucharest http://www.uauim.ro/evenimente/simpozion-arhitecturi-contemporane-2017/
} 


\section{In searching of demarche performance: diploma projects}

\section{Introduction}

Present article proposes to present the architecture diploma projects as double educational paradigm: synthetic cumulative answers to/and in parallel with formulating projects themes, and educational strategy (UAUIM, 2017) for academic-university validating for targeted levels - intern, national and international. Parallel identification of final priorities of the projects and targets to reach in university education (UAUIM, 2017) is the proposed method for evaluating academic success. Also, fulfilling and correlating the international standards at academic but also architectural products level, are other few priority targets. In other words, the level of knowledge, thematic orientation and professional formation are targets to correlate with the level and curricular and formative priorities belonging to local, European and international schools of architecture.

The article aims to talk about architectural diploma projects as a contemporary status aligned with the dedicated performing domain. Most diploma projects are looking for new professional emergencies, an applied model or competition of ideas, participating in a permanent contest of ideas and expression, many militating for a status / statement, but also for redefining theoretical fundamental visions. Diploma projects in themselves are and are required architectural declarations of design- some achieve their own announced bar, others cling to small details of the manufacturing process. Many diplomas are a real success in the synthetic approach of architectural design - as the final results, and in the search for the elements of performance marking: detailed production of a final result of excellence.

The article does not intend to define the school of architecture, but the successful and the average results of the diploma projects bring and bring to foreword the educational excellence and can re-establish it on the top performance map of the field. The present moment finds UAUM as an architectural school with an upward performance of more than 20 years in a process of continuous modernization and connection to innovative and technological standards. UAUIM keeps and works on its identity and vision as the school of architecture, through the architectural design studio, the synthetic basis of academic (architectural) pedagogy, a studio that is constantly supported and correlated with the cultural and social context - national and international - in flexible ways of teaching and supporting the didactic process adapted by tutorial guiding teams (by mentors - professors), aiming at the development of formative skills integrated into the future profession, in the current extended variants international offers.

\section{Methodology}

Methodology of the article is based on the labeling principles and results, and in parallel on the analysis of responses - especially of the collection of answers and success examples. The authors are preoccupied on subject of education as curricular reflection but also as research reflection, because of their enrollment as tutors within the integrated master (degree) synthetic process, and correlated with the main (architectural) contemporary research topics reflected also by the education process, and research by design, inclusive at the learning level exercise.

The article wishes to be also a review of organizing and validating diploma for school of architecture, reflected within activity of International Academic Relations Office, "Ion Mincu" University of Architecture and Urbanism Bucharest. Activity of organizing the international 
diploma projects committees, as well as the experience of discussions sessions and round tables (Annex 1, Annex 2) with members from international committees on which professors - academic staff members from UAUIM / IMUAU are participating, is one of the relevant outlines of the present paper - principles communication and the analysis of the results. Another experience situated at the basis of the article is the discussion evolution between the members of UAUIM / IMUAU (UAUIM, 2016) - ACE (ACE, 2016) - AEEA (AEEA, 2016) on the development of international competition for architecture medal on diploma projects: EAM European Architectural Medals for the Best Diploma Projects (EAM BDP) (EAM BDP, 2016). Also other premises of formulating few increases in competences is underlined by the new tradition of international collaborations within IAESTE (IAESTE, 2016), collaborations based on supporting applied training - practice work within architecture offices. An eloquent review for the architecture diploma projects is constituted by the publications and visual albums on best diplomas UAUIM / IMUAU, but also on every edition album EAM BDP, and not at least by the illustration visual panels with diploma projects submitted to ANUALA Arhitectură București (Architecture Bucharest Annual, organized by OAR - Order of Romanian Architects) (ANUALA, 2016).

\section{Diploma projects within school of architecture}

\section{Architectural - educational demarche}

If architecture could be understood as a generic term and is seen as a structure, a thinking module of conceiving objects, so architecture of architecture how might be perceived? Interpreter term of architecture to its own education, a system of thinking is implicit forming the future architects as sustainable products within applied and/or theoretical practice domain. Not in vane, an own system of thinking, explicable only for the few ones becomes a way of communication between members of architecture academia from everywhere, both professors and students. From choosing a method to choosing the best solution for a demarche, illustrations from the technical to conceptual, and the ones of decision, have become the mark of the domain. For example the book of architectural ideas of Matthew Frederick (Frederick, 2007) illustrates a way of thinking specific for the school of architecture from everywhere - in a specific language of architectural idea construction - graphical followed by key words and short descriptions of systemic considerations that have already made history of the field.

Named specific to some criteria with educative result - integrated master, the last level of application of knowledge proposes through architectural exercises - projects within architectural design studios to set up the basis of accumulated learning from every educational levels and of formative courses, together with learning methods, that in final to be able to propose future architects to formulate complex project design - with questions and solutions, its own thematic and conceptual demarche, to test both systemic reflections, connection to architectural contemporary concerns and emergencies, but also of an own (qualitative) contribution which professional future will bring to the domain space (Irșai\&UAUIM, 2011).

Many times the Architecture of Architecture will content besides abilities and competences written and expressed through curricula, manners and considerations multiple algorithm, both counting for establishing the formal stability of learning but also applying tutoring/ mentoring guidance within architectural design studios. From collecting ideals to the decoding and setting 
up the first equation of a beginning, to the framework of a conceptual demarche and architectural path, the projects - as formal sub products of education- are situated between the overview design ability, applicability and an integrated format to real and educational correlated possibilities.

Foundation of education and architectural culture for many successful architects at national and international level, the UAUIM Architecture School favors the level of the tradition of working and elaborating the detailed project, and within the over past 20 years gains expertise in supporting the design performance motivating the consistency of conceptual statements, becoming an academic space with artistic inclinations but with real practical valences and technical abilities.

Academic experiments and experience, but also based on architecture practice are demonstrating also other inputs for inserting in university searching: artistic sensibility and creativity cultivation (Mitrache, 2013), aural pedagogy... (Bărbuică, 2013), but also of complementary abilities and formative skills trained outside the time dedicated to the curricula, and specific within workshops developing/ or studios based on research-discussion and debate-innovation in architectural thinking (Sfinteș, 2017).

The results of the diploma projects are the result of the training in the architectural design studio, carried out over 12 semesters, under the curriculum integration and workflow approach as a working method in architectural thinking. Often a properly supported approach and the validation of all design verification points can support and ensure a quality or excellence result. Sometimes, the artistic side, sometimes intuited, and then checked through the integrated design list, is the recipe of a brave approach that puts the school of architecture in the forefront (for example: the medals awarded many UAUIM graduated students).

\section{Discussions on (final) project design: the diploma}

Could formative education from architecture field be a way to "architecture"/ structure Architecture?

The result analysis on the projects diploma could be a verifying instrument for sketching the future priorities and of new educational abilities to train. Misunderstandings from the students projects within the architecture education are proving our results are not always at the best level or there is a gap in fabricating architectural design (in architectural educational project), but equally the successful results of the students could set a high level of architecture school to be proud of. The misconceptions from these projects designs could oppose algorithms of minimal educational coherence to ones of sustainability for the future professional specialist: 1.complicated vs. complexity in enouncing the architectural design thinking, 2. applying some random fashions vs. formulating sensitive-compositional principles, 3. formal ungrounded stylistics vs. enunciating principles starting from the interface dedicated to space/from design, 4. implementing some standard detailing vs. shaping solutions based on own design, 5 . elements of scholastic sustainability vs. a sustainability that responds on all responsible layers, 6. narrative subject vs. thematic emergency.

On other direction, exhibitions with best diploma projects (two sessions of annual public defense having international jury) prove some durable principles implementing for shaping abilities and demonstrating the necessary competencies for a sustainable thinking for the future architect, product of school of architecture (Barac, 2012). Two general tendencies could demonstrate the high educational level through diploma projects within the school of 
architecture: the model and the ideas competition that are included to the models - the contest or comparative exhibition for choosing the most significant models for enunciating the direction of education belonging to the architectural academic environment (Dobre, 2016).

Visibility of diploma projects is reflecting contemporary interpretative manners, but also contented ideas. These are guiding the projects towards an architectural model - exposure type model-competition being included to a competition regarding results: RIBA part II accreditation of the graduates diplomas - being a target for school of architecture, -OAR ca professional guild validating the internationalization of diploma process and priority standards verification for universities through international juries session for diploma projects: Alumni together with IAESTE (Comşa, 2012) ensuring post academic patterns verification and mentoring process. The opening of the Architectural Annual Bucharest towards final selection of the exhibition submission of the diploma projects, supports same educational demarche, encouraged as being a continuous one also within the carrier (of architecture).

More, the development of the two editions of the international competition for architecture diploma projects EAM - European Architectural Medals for the Best Diploma Projects (EAM BDP) - organized by UAUIM / IMUAU in partnership with AEEA and ACE - , value besides the abilities formation needed for the architect profession, also a synthetic decisional and critical thinking upon premises organizing, formulating questions and of the correlated decisions for targeting a final notable result.

\section{From critic to architecture - results and synthesis in architectural design}

Education in schools of architecture may be different, but it is structured similar on few closed curricular principles, beyond country or education system - arts school or technical school based. Competencies are formulated very similar, but the results could be very different. The diploma project (together with dissertation - research study that accompanies the diploma along evolution demarche shaping) could be considered a final and maturity exam - it validates or invalidates sometimes the architectural product, thus resulting different direct conclusions. The general competences are referring to the capacity of conceiving valid projects, aesthetically and technically. Competencies oriented towards emergent research (Jöger et al., 2016) domains - arts humanities (including visual and performative arts, philosophy and history), social sciences (including urbanism, social actions, landscape, urban context and design), technology and spatial structuralism, and applicative elements in constructions domain including sustainability (RIBA, 2012).

Similar to expressionist art of Pollock (Art-Madrid, 2018), architecture is in permanent redefinition of algorithms with increasing complexity. Reloading the comparison probably it could be not only the subject of an equation setup relating with other domains of social and communicational enrolment (Mihaila, 2014) but also of an equation fractal expressionist. Even if for its own members it could appear always uncommunicative or unfocused, architecture remains a top domain, influenced always by the schools of architecture tendencies but influencing back the education, standards and redefining the history of the field though the emergency of recent (striking) walling.

Mentoring remains a basis principle, an educational model that builds relations and influencing the domain directly beyond the boundary of the school of architecture, including the profession (Mihaila, 2015). So, the development of integrated criteria on all educational 
products (AEEA, 2016) categories - fro the project to the future architect, from the member from the tutoring team to the main mentor, and to the curricula, all these should be the role of a single integrated thinking. Assuming strong and weak points of periodical evaluations (UAUIM, RIBA\&EUA, 2016) constitutes an assumed thinking in architectural design, similar to a critical thinking upon the educational products oriented towards immediate sustainable results. Concluding, architecture critic could be the applicable basis of a succinct analysis included critic for the priority defining level of school of architecture, towards the model of conceiving of a project to diminish errors and prevent risks. The result of a critical analysis in forming abilities and demonstrating competencies could constitute a system of verificationcommunication on multiple levels of few common managerial and curricula's principles implication, simple in appliance, with multiple targets, for a sustainable professional spacetime, and for rethinking a system of educational products: project-student-future professionalarchitectural community.
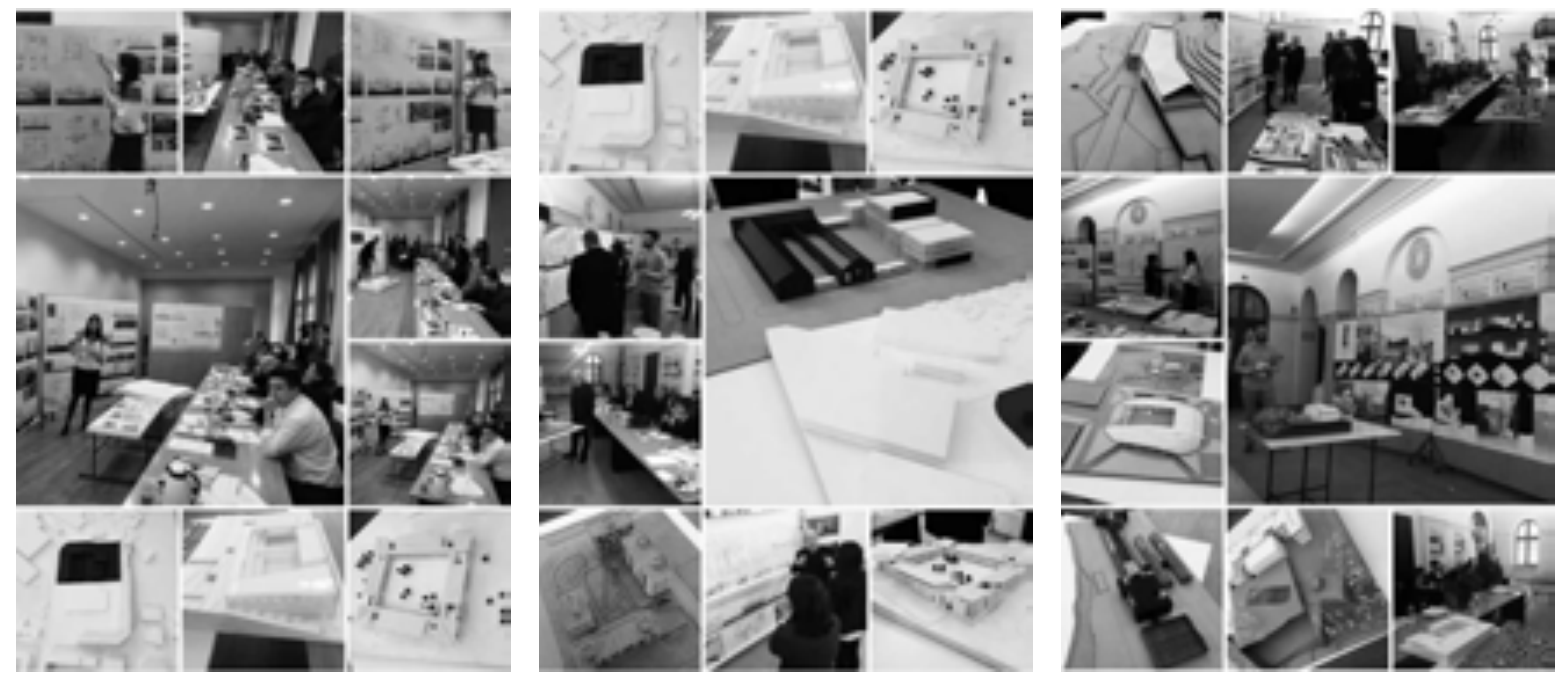

Fig. 1. Photo-collage illustration: atmosphere of international committees for diploma project jury (session March 2017), Faculty of Architecture, UAUIM / IMUAU. Source: facebook page, RAI Office, UAUIM / IMUAU (UAUIM, 2017)

\footnotetext{
RIBA A Diplomele de arhitect conferite de Facultatea de Arhitectură sunt validate RIBA (Royal Institute of British Architects) ca urmare a evaluSrllor periodice efectuate in 1998, 2001, 2007 si 2012.

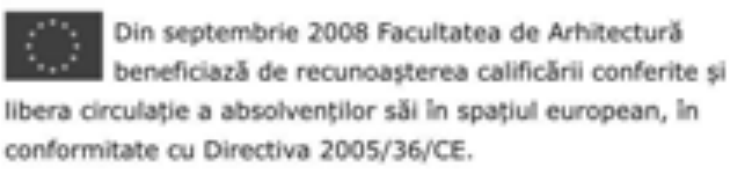

Fig. 2. „Architecture Diplomas emitted by Faculty of Architecture are validated by RIBA (Royal Institute of British Architects) as a result of periodic evaluations accomplished in 1998, 2001, 2007 and 2012”; "From September 2008 Faculty of Architecture beneficiates of the recognition of qualifications and free movement circulation conferred on its graduates architects within the European space, according with Directive 2005/36/CE.". Print screen, UAUIM / IMUAU site (UAUIM, 2017) 

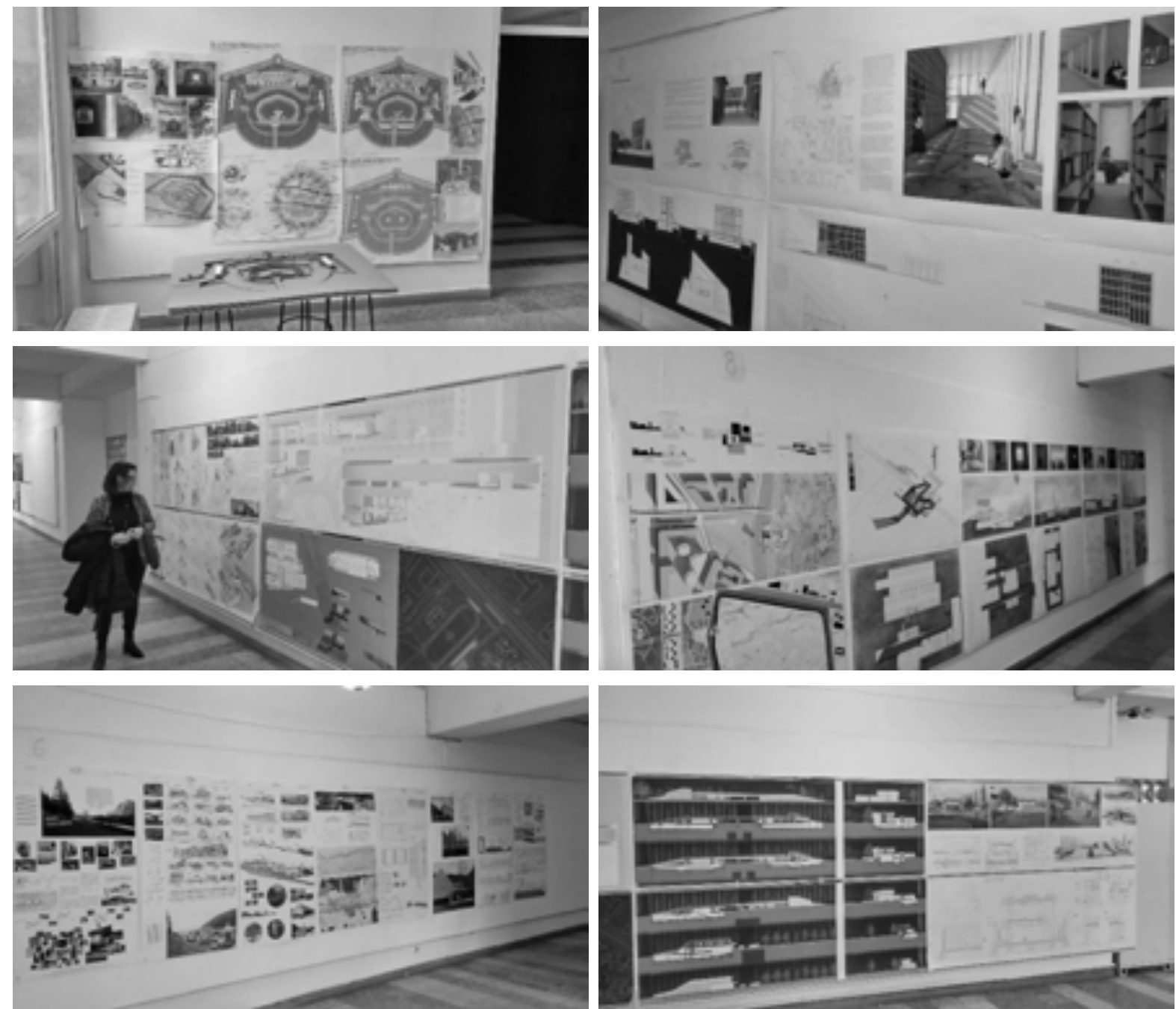

Fig. 3. Images from the best of the best diploma projects, session March 2017. Photo: Daniel Comsa, 2017.

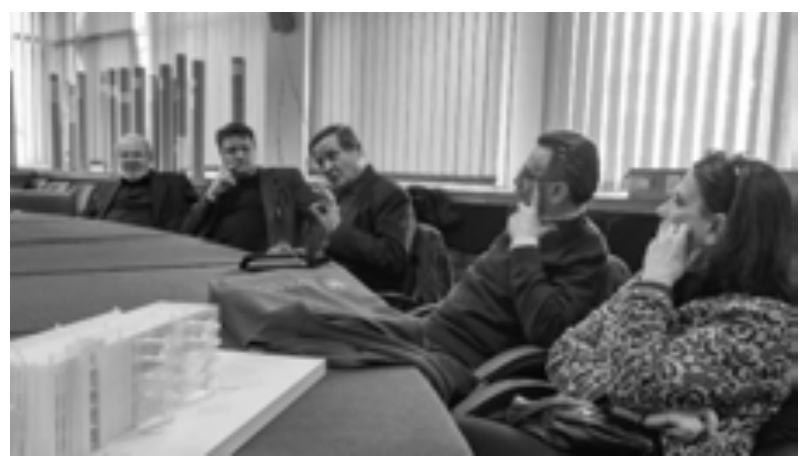

Fig. 4. Round Table: Conclusions Diploma Projects Committees Session March 2017, Council Hall, UAUIM: Professors' discussions; in image: Professor arch. James Horan - Ireland, Professor arch. Vlatko Korobar Macedonia, Professor arch. Juhani Katainen - Finland, Professor dr.arch. Ferenc Sebesteny - Hungary \&

Professor arch. Alessandra Capanna - Italia. Photo: Daniel Comsa, 2017. 


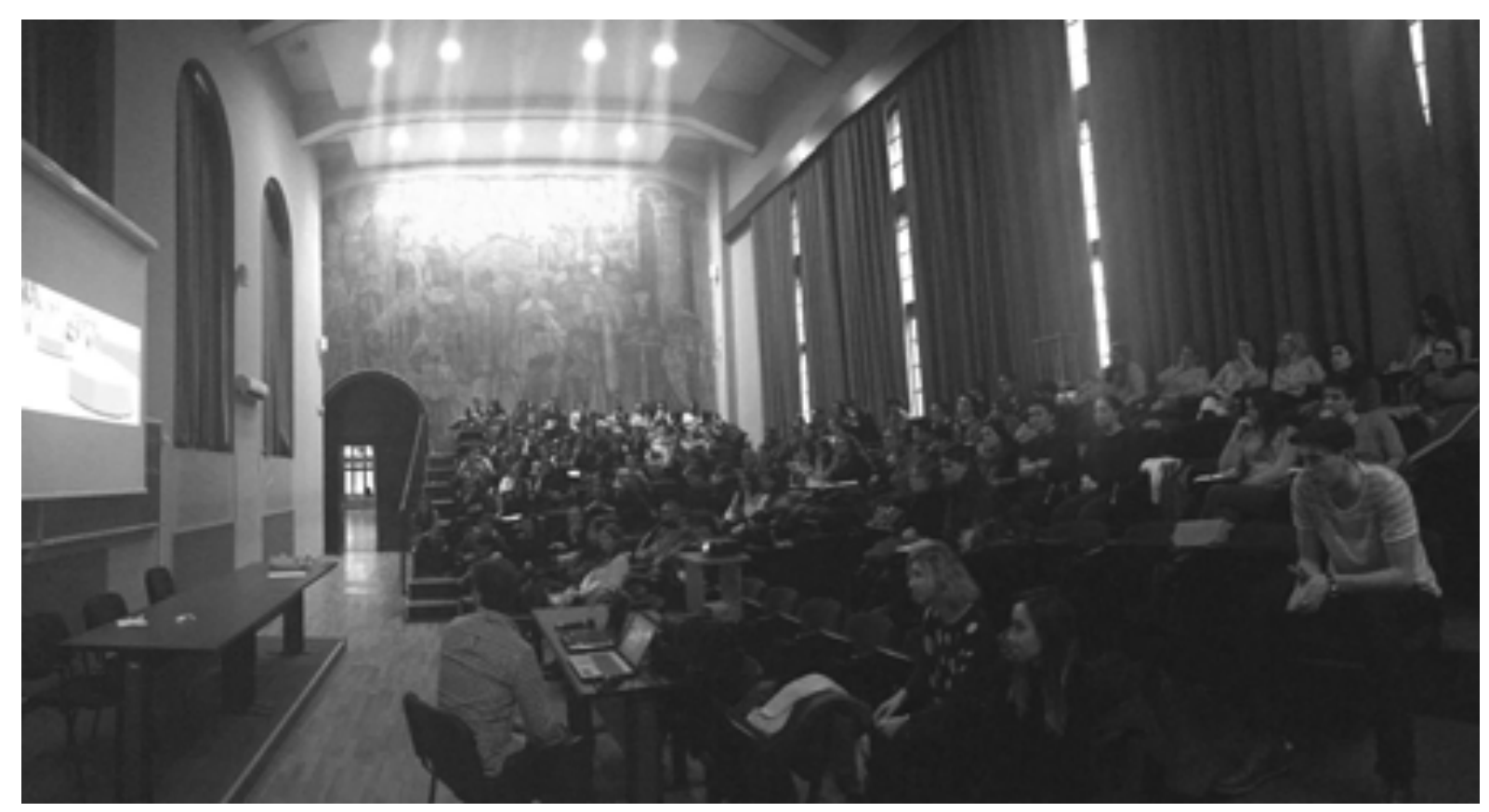

Fig. 5. Fresco Hall, UAUIM / IMUAU Bucharest - image from the interactive conference IAESTE for dissemination information and places for architecture practice, March 2017 - in which IAESTE participating students have presented their traineeships and professional experiences. Photo: Marina Mihaila, 2017.

\section{Annex 1. Round table: conclusions DIPLOMA PROJECTS SESSION UAUIM 7th July 2017}

\section{Summary}

Round table: conclusions Diploma Projects Session July 2017 (5-6th July 2017), UAUIM, gathered on the 7th July 2017 in the Council Hall UAUIM, Bucharest, the member of the university management, professors participating within the Jury Committees (11 Committees, 8 members +1 secretary per each committee, 2 general coordinators chairs) and university academic staff among which tutors of the diploma projects.

The meeting was initiated by the UAUIM's Rector Prof.Dr.Arch. Marian Moiceanu and School of Architecture's Dean Prof.Dr.Arch. Georgică Mitrache, presenting the synthetic results of the Diploma Session and the process of voting the best diploma - the round table was preceded by the Best Diploma Projects Exhibition, and the professors participating within the Jury Committees were invited to vote for the best project exhibited. After the procedure of voting and choosing the three best diploma within the present session, the discussions were initiated, and each professor enunciated his/her opinions on the level of diploma projects (from each committee) and the level of students, topics, importance of the themes, relation with arts and urban context, architectural programs design and complexity of approach and result. As a general input from the professors' conclusions - propositions, this year the level of students increased spectacular on English presentation knowledge, discourses and dialog in architecture and expressing the positive results of their projects, as well as it was noticed an increased number of good projects in comparison with the last years, as much as the weak approached projects noticed continuing to exist, and entering in the diploma jury process. Debating the process of accreditation and certifying system of quality in education as verified by the 
development of international Diploma Committees/Juries, few results of the discussions were: the recommendation of all the phases of the project to be exposed - especially the Prediploma (the pre-design), the underlying of the project process and conceptual thinking within the final exposure of the diploma, also working with the model and expression of architecture to ensure a contemporary architecture vocabulary and result. The round table was chaired by the UAUIM's Rector Prof.Dr.Arch. Marian Moiceanu and School of Architecture's Dean Prof.Dr.Arch. Georgică Mitrache, and also by the General Coordinators chairs: Pres.Prof.Dr.Arch. Emil Barbu Popescu and Conf.Dr.Arch. Daniel Comșa, Head of International Academic Relations Office.

\section{Annex 2. Round table: conclusions DIPLOMA PROJECTS SESSION UAUIM 3rd March 2017}

\section{Summary}

Spring Diploma Projects Session is organized as second international jury commission series, gathering between 3 and 6 committees, with usual number of professors within the committee - 8 (3 international jury commissions this session, March 2017). Round table: conclusions DIPLOMA PROJECTS SESSION 3rd March 2017, UAUIM, developed an extended discussion on the level of the school of architecture, based not only on the presence of the best and excellent diploma projects but also evaluating the majority and the level of the weak projects. This discussion is a present inquiry within the worldwide schools of architecture, targeting the feedback as response from educational results, together with the expectations of the future specialists, architects. Professors' observations were connected with applauding the best results, much more present and perfomant that in the last years, recommendations on standardizing the presentation - both oral and on paper - , the mandatory presence of declaration on architecture interest, conceptual outputs, and the history of the project, maybe an introduction made to the committee before the diploma project public defense. The recommendation regarding followed presentations were: focus has to reach also technology and research, as well a study form on the model, relation between prediploma (predesign) and the diploma have to be discussed, and the references of the former commissions have to be underlined. Other prescriptions related to the admission (having a positive notice from the tutors) within the diploma sessions for projects public defense, and the presence of lower grades/years of study students for assistance and learning from this experience of discussing the final projects of graduation. The round table was chaired by the UAUIM's Rector Prof.Dr.Arch. Marian Moiceanu and School of Architecture's Dean Prof.Dr.Arch. Georgică Mitrache, and also by the General Coordinators chairs: Pres.Prof.Dr.Arch. Emil Barbu Popescu and Conf.Dr.Arch. Daniel Comșa, Head of International Academic Relations Office.

\section{References}

AEEA / EAAE. EAAE GA \& CONFERENCE 2016. (2016). A case study discussed in the context of institutional profile(s) and the future of architectural education. Delft: TU Delft Faculty of Architecture. pp. 53-54

Barac M. (2012). Ion Mincu University of Architecture and Urbanism, Romania. in The Architectural Review 232(1386). pp. 108-109 
Bărbuică L. (2013). Towards a New Aural Pedagogy for Architecture. in Procedia Social and Behavioral Sciences 92. pp.92-97

Comşa D. (2012). The cultural role of the international exchanges on architectural education through IAESTE. in Proceedings Book ICAR2012, Chapter: Beyond discipline(s) - architectural education and research, Bucharest: EUIM.

Comşa D. (2014). Architectural competition seen as a research method. in Lucrarile Conferintei de Cercetare in Constructii, Economia Constructiilor, Urbansim si Amenajarea Teritoriului, Volum 1-8 2011 2014, Chapter: Arhitectura, (Eds.): A.Petrișor, V.Meiță Bucharest: NR\&DI URBAN-INCERC. pp. 15-16

Dobre A-M. (2016). „Examenul de Stat” şi Proiectul de diplomă în Şcoala românească de Arhitectură a anilor '50. / Final Exams and Diploma Project in the Romanian School of Architecture of the 50's. in Argument 8/2016. pp. 47-60

Frederick M. (2007). 101 Things I Learned in Architecture School. London: MIT Press.

Jöger B., Comşa D., Panait A., Mihaila M., Zamfir (Grigorescu) M., Diaconescu O., Sfinteş A-I., \& Armenciu D.N. (2016). Building an Architectural Discourse_ A Review on Scholarly Academic Space, UAUIM. in EURAU 2016 Proceedings. pp. 445-452

Mihaila M. (2014). Communicating Architecture - activities, actions, exercises, mission statements. in LUMEN: Transdisciplinarity and Communicative Action. Bologna: Medimond Monduzzi International Proceedings 2014. pp. 465-469

Mihaila M. (2015). Mentoring Architecture: Contemporary Status as Overview. in Working Papers LUMEN MEPDEV 2015, lași: LUMEN, 2015. pp. 265-266

Mitrache A. (2013). Spatial sensibility in architectural education. in Procedia Social and Behavioral Sciences 73. pp.544-548

Sfinteș A. (2017). Workshop: Locuri În Afara Limitei / Places Out Of The Limit. in Argument 7/ 2017. pp. 395-406

\section{Webography}

ACE. (2016). The Architects' Council of Europe. 2016. http://www.ace-cae.eu/ (accessed 8.04.2017)

AEEA / EAAE. (2016). European Association for Architectural Education. http://www.eaae.be/ (accessed 8.04.2017)

ANUALA. (2016). Anuala Arhitectură București / Bucharest Architecture Annual. 2016. http://www.anuala.ro/ (accessed 8.04.2017)

Art-Madrid. (2016). Pollock is Pollock. 13th Contemporary Art Fair, Feb.2018. http://www.artmadrid.com/en/news/Jackson-Pollock-A-Collection-Survey-at-MOMA-Museum (accessed 8.04.2017)

EAM BDP. (2016). European Architectural Medals for the Best Diploma Projects. https://eam.uauim.ro/ (accessed 8.04.2017)

IAESTE. (2016). The International Association for the Exchange of Students for Technical Experience (IAESTE). http://www.iaeste.org/about-iaeste/ (accessed 8.04.2017)

Irșai I. (2011). Universitatea de Arhitectură şi Urbanism „Ion Mincu”- Bucureşti, Facultatea de Arhitectură, 6-7 Iulie 2011. in Arhitectura, 2011. http://arhitectura-1906.ro/2011/10/universitatea-dearhitectura-si-urbanism-\%E2\%80\%9Eion-mincu\%E2\%80\%9D-bucuresti-facultatea-de-arhitectura-6-7iulie-2011/ (accessed 8.04.2017) 
OAR. (2016). Ordinul Arhitecților din România (Romanian Architects Order). http://www.oar.archi/ (accessed 8.04.2017)

RIBA. (2016). Royal Institute of British Architects. https://www.architecture.com/ (accessed 8.04.2017)

UAUIM / IMUAU. (2016). "IOn Mincu” University of Architecture and Urbanism" Bucharest. http://www.uauim.ro/ (accessed 8.04.2017)

UAUIM / IMUAU. (2016). Plan de învățământ 2016-2017, anul VI (sem. 11 și 12). Curriculum 2016-2017, 6th year (sem. 11 and 12). http://www.uauim.ro/facultati/arhitectura/arhitectura/planuriinvatamant/6/ \& http://www.uauim.ro/en/faculties/architecture/architecture/curricula/6/ (accessed 8.04.2017)

UAUIM / IMUAU, Moiceanu M., Mitrache G., \& Stănculescu M. (2016). Studiul de Fundamentare a Prediplomei 2016-2017. (Fondation Study for Diploma Project). Departamentul Sinteza Proiectării de Arhitectură. (Synthesis of Architectural Design Department), 2016. http://www.uauim.ro/departamente/sp/teme6/

http://www.uauim.ro/departamente/sp/teme6/2016-

2017/Studiul\%20de\%20fundamentare\%20a\%20prediplomei\%202017 (accessed 8.04.2017)

UAUIM / IMUAU. (2016). Ghidul Studentului (Student's Guide) 2015-2016/ 2016-2017. Bucharest: Editura Universitară „Ion Mincu”, 2016. pp. 57-71 http://www.uauim.ro/facultati/arhitectura/ \& http://www.uauim.ro/facultati/arhitectura/Ghidul\%20studentului_ARHITECTURA_2016-2017.pdf (accessed 8.04.2017)

UAUIM, RIBA \& EUA. (2016). Managementul calitatii educatiei - Raport RIBA, raport EUA etc. UAUIM / IMUAU. "IOn Mincu" University of Architecture and Urbanism" Bucharest. 2016. https://www.uauim.ro/universitatea/managementul_calitatii_educatiei/ (accessed 8.04.2017)

UAUIM. (2016). UAUIM Facebook page: facebook page RAI Office - International Academic Relations Office, UAUIM / IMUAU: https://www.facebook.com/UAUIM-International-Academic-Relations-Office701443153359998/ photo before collage : Marina Mihaila, Marius Voica, 2017 (accessed 8.04.2017) 